\title{
Influence of Enzymatic Agents on the Ginkgo Fruit Ratio using Nano-Processing Technology
}

\author{
Seung Hyun Lee ${ }^{1}$, Seung Min Lee ${ }^{2}$, Soojeong $\mathrm{So}^{2}$, Yun-Sik Choi ${ }^{3}$, Kyung-Min Kim ${ }^{4 *}$, \\ Il Kyung Chung ${ }^{*}$ \\ ${ }^{1}$ Department of Biotechnology, Daegu Catholic University, Gyeongsan-si, Gyeongsanbuk-do, 38430, Korea \\ ${ }^{2}$ Institute in Natural Science Techonolgy, Gyeongsan-si, Gyeongsanbuk-do, 38430, Korea \\ ${ }^{3}$ Department of Pharmacology, College of Pharmacy, Kyungsung University, Nam-Gu, Busan-Si, 48434, Korea \\ ${ }^{4}$ School of Applied Biosciences, College of Agriculture \& Life Sciences, Kyungpook National University, Daegu, \\ 41566, Korea
}

\begin{abstract}
*Corresponding Authors: Kyung-Min Kim, School of Applied Biosciences, College of Agriculture \& Life Sciences, Kyungpook National University, Daegu, 41566, Korea.

Il Kyung Chung, Department of Biotechnology, Daegu Catholic University, Gyeongsan-si, Gyeongsanbuk-do, 38430, Korea
\end{abstract}

\begin{abstract}
We investigated the effects of a preparation by wet nanotechnology on the pollen, pistil, and fruit loss in ginkgoes. Pollen germination in the test medium was investigated by adding insoluble calcium and magnesium nano particles. The germination rate increased $30 \%$ after $72 \mathrm{~h}$; however, pollen in germination medium to which $1 \mu \mathrm{L}$ agitating agent was added did not germinate after $72 \mathrm{~h}$. Thus, the nanoized emulsifier inhibited germination of ginkgo pollen. Fruit loss rate for ginkgo seedlings sprayed with nanoized reding agent decreased by 60-90\% more than that of unsprayed fruit. However, 4 days following the application of the re-deposition agent, the content of calcium and magnesium in the ginkgo pistils decreased, requiring reapplication within 3 days. The soil pollution test confirmed the enrichment agent did not affect surrounding soil, and it will be applicable to various roadside trees in addition to ginkgoes. Because the external environment may affect success (e.g., spraying method, rain, and wind), it is necessary to set a spraying and reapplication time. The wet nano-process technology is expected to be applicable to various fields, and can be used in natural materials and bioindustries, as well as for plant nutrients.
\end{abstract}

Keywords: agitating agent, bioindustries, ginkgo, nano-process, pollen

\section{INTRODUCTION}

The ginkgo tree (Ginkgo biloba), which is common in Korea, is an example of a "living fossil" that existed on earth approximately 350 million years ago. It is a deciduous tree of Chinese origin. The bark is gray or grayish brown with thick cork and deep vertical cracks. Leaves appear gathered on the short branches. The leaves are often fan-shaped and divided in two. There is a fine wavy pattern on the edge of the leaf, but both sides are plain yet majestic. Ginkgo is a migratory plant being the sole species in the genus, but has eight varieties. It is difficult to identify gender in young plants, making it difficult to selectively plant trees because ginseng gender can only be distinguished after approximately 15 years. The ginkgo genders grow as separate trees. In April-May, flowers of approximately $3 \mathrm{~mm}$ bloom widely over the tree. The number of male flowers is $1-5$, the female flowers are green and there are 6-7. Two pedicels each have $2 \mathrm{~cm}$ peduncles, but only one of them grows and ripens in October. The fruit of ginkgo, which is ripe in the fall, is oval to round with a fleshy shell for an outer skin with a pulp inside, and the flesh of the surface of the fruit has an unpleasant odor because of the ingredients bilobol and ginkgoic acid. It can cause irritation to human skin. Because of this odor and potential contact inflammation, other animals do not eat the ginkgo nut; 
only human beings do so. In areas planted with ginkgo trees, complaints regarding ginkgo fruit are very common. To solve this problem, we could replace the ginkgo trees or remove the fruits early before they ripen. In Japan, to solve the odor problem caused by ginkgo fruit, all the ginkgo trees were replaced with other trees. However, the pollen from the male trees during the flowering season has to be removed every year to prevent bronchial diseases, such as allergies and rhinitis [1-2] (Wada et al., 1985; Singh et al., 2008). Symptoms, such as vomiting and spasms, are also caused by ginkgo seeds and street pollution reduces the daily quality of life [3-5] (Yamaguchi, 1977; Jung\& Rho, 2010; Kajiyama et al., 2002). Therefore, it is necessary to properly control the number of ginkgo fruit trees to prevent unpleasant odor from the fruit. In the case of fruit trees, fruit reduction is conducted to inhibit fruit juice and to improve quality for high-quality fruit production. Antioxidants are commercially available drugs that can be sprayed on trees at appropriate times to inhibit the growth of flowers and prevent reproductive tissue formation, or to inhibit pollen scattering by coating male flowers. Plant hormones and organic synthetic substances are available. The use of drugs that have been discovered as a side effect of insecticidal effects is limited, and a variety of products are mixed [6-8] (Byers, 2003; Mahvash et al., 2009; Kim et al., 2008). To solve the odor problem of Ginkgo biloba, we studied the effects of an enrichment agent prepared by wet nano grindings on the seeds and pollen of Ginkgo biloba before flowering with a method to suppress fertilization and regulate seed loss rate and produce a harmless agent. The effects of coating the ground and pollen, and fruit loss rate was investigated.

\section{EXPERIMENT SECTION}

\subsection{Materials}

The Ginkgo biloba used in this study was collected and identified directly from Cangkyong University, Suwon, Daegu, Haeyang, Gyeongsan, Gyeongsangbuk-do.

\subsection{Application of Wet Nano Powder}

The Ginkgo biloba extract prepared in this study was prepared by dispersing insoluble calcium and magnesium, which are insoluble in water, in water using nanotechnology. It was prepared using a rotary mill (Amstech Co. Ltd., South Korea).A magnetizing agent containing magnesium was pulverized for $5 \mathrm{~h}$ or more, because the absorption rate increases with the reduction in particle size after ultrafine pulverization [9] (Zhang \& Zhang, 2005). The nanoparticle size was confirmed using a particle size analyzer (Nano ZS, Malvern, UK).

\subsection{Nanotechnology Process}

The nanotechnology used in this study was wet nanoparticle grinding technology, which is becoming increasingly important in biotechnology and medicinal developments. It is suitable for grinding raw biological materials, such as cells, and it is a technology that is processed using ring mill equipment. The principle of the ring mill is that the raw material flows into the interior of the dispersed vessel, collides with the beads in the interior of the dispersed vessel, and is then crushed and passed through the screen to the outside of the vessel. Through the repetition of this process, the particles become smaller and eventually nanosized. The agitation agent used in this study was prepared by mixing $10 \%$ calcium acetate, $15 \%$ calcium carbonate, $2 \%$ magnesium carbonate, $0.5 \%$ zinc sulfate, $0.14 \%$ boric acid, and $0.5 \%$ tween- 80 in the total weight of the preparation. The particle size of the redeposited agent was gradually decreased according to the time of the nanoization process, and when the powder was pulverized for $4 \mathrm{~h}$ or more, a formulation with particles of approximately $700 \mathrm{~nm}$ or less could be produced (fig. 1). 

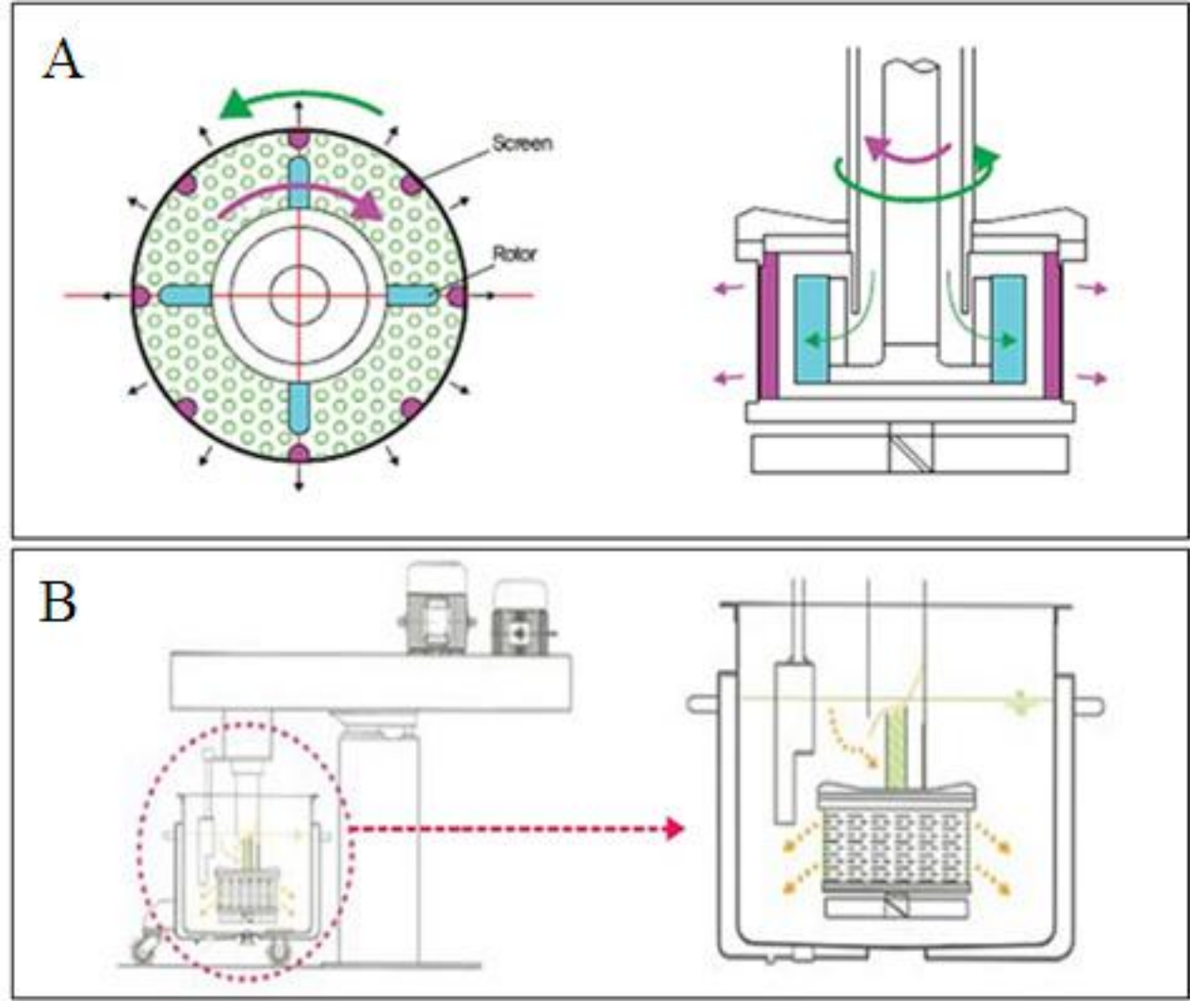

Fig1. Ring mill equipment. A: Principle of wet nano grinding equipment, B : Flow chart of wet nano grinding.

\subsection{Effects of Media on Gingko Pollen Germination}

The bank pollen used in the experiment was obtained from the ginkgo operation at the Catholic University of Daegu, Gyeongsangbuk-do. A $1 \mathrm{M}$ Mes- $\mathrm{KOH}$ (pH 6.0) solution was prepared and 2.85 $\mathrm{g} / 50 \mathrm{~mL}$ of $20 \mathrm{mM}$ Mes-KOH (pH 6.0) to be used for pollen media was prepared and $5 \mathrm{~mL}$ was pipetted to prepare $70 \mu \mathrm{L}$ of pollen media $\left(\mathrm{Ca}\left(\mathrm{NO}_{3}\right) 10 \mu \mathrm{L}\right.$ of $\mathrm{MgSO}_{4}, 10 \mu \mathrm{L}$ of $\mathrm{KNO}_{3}, 10 \mu \mathrm{L}$ of $\mathrm{H}_{3} \mathrm{BO}_{3}$ ). Then, $20 \mathrm{~g} / 100 \mathrm{~mL}$ of sucrose was mixed and used [10] (Brewvaker \& Kwack, 1963). Sucrose was added to $20 \mathrm{~mL}$ of $1 \mathrm{M}$ Mes-KOH in $1 \mathrm{~mL}$ E-tubesto the desired concentration. The prepared medium was referred to as pollen germination medium. The ginkgo seedlings obtained from

Ginkgo biloba placed in $10 \%, 15 \%$, and $20 \%$ pollen germination media and stored at $28^{\circ} \mathrm{C}$ for $24 \mathrm{~h}$. As a control group, the germination conditions of the bank pollen were confirmed by optical microscope in the pollen germination medium containing the nanotechnology-red pepper.

\subsection{Ginkgo Paint Coating Component Analysis}

The bank pollen was fixed on a sample holder and plated in a Cressington 108auto scanning electron microscopy (SEM) sputter coater machine and plated for approximately $55 \mathrm{~s}$ at $35 \mathrm{~mA} / \mathrm{mbar}$. Electron beam SEM and energy dispersive spectrometry (EDS) was used. The calcium and magnesium contents of the experimental group were analyzed and the effect of the nanotechnology, and the application of an oxidizing agent to the calcium and magnesium content of the control was examined [11-13] (Yoo et al., 2016; Park et al., 2013; Kim et al., 1998). An electron microscope is a microscope that uses an electron beam instead of the visible rays used in a light microscope, and an electron lens instead of a glass lens. It is a device that enables highly magnified images. The lens action for electrons is similar to that of collecting electrons as the convex lens focuses light, and it changes the current flowing through the coil by using a magnetic field to warp the movement path of electrons. Because the electron beam is used instead of the light beam, the inside of the microscope must be in vacuum. The former is difficult to control as desired because energy collapses or refracts when it collides with air. The magnification was determined by the intensity of the electric current passing through the intermediate lens, and the coil of the projection lens, whereas the distance between the specimen and the objective lens is constant, and the focus of the image is controlled by the current 
flowing through the coil of the objective lens. Elastic scattering and inelastic scattering occur as the electron beam collides with the surface of the sample. Secondary electrons, reflection electrons, characteristics, and continuous X-rays caused by inelastic scattering, phonons caused by lattice vibration, and so on. The EDS (Energy Dispersive Spectrometry) is an optional feature attached on the SEM, and it is a component analysis device [14] (Kim, 1993). The principle of the component analysis is to use X-rays. When the electron beam is scanned in the specimen, it becomes excited by the energy in the atom. When the electrons generated at this time have stabilized, a specific X-ray is emitted. Because each substance has a different intrinsic energy from which a specific X-ray is emitted, it is necessary to analyze the constituents of the substance through this value.

\subsection{Efficacy of Ginkgo Biloba Spraying}

To observe the effect of enrichment of ginkgo seeds using the redeveloping agent prepared through the nano-manufacturing process, four trees were selected from Baeam-myeon, Yongin city, Gyeonggi-do, and sprayed three times at intervals of 2-3 days with 50L per week. The gingko fruit loss results were compared by obtaining gingko fruit as a control.

\subsection{Soil Pollution Process Test in the Area Sprayed with an Emulsifier}

To confirm the soil contamination level of the spraying area, $1 \mathrm{~kg}$ of each soil was collected from each soil spraying area and the spraying area in Gyeonggi Province and each was labeled in a vinyl pack and stored at room temperature. The soil pollution process test was conducted by selecting one of five samples from the Korea Environmental Water Research Institute. The test items were cadmium, copper, arsenic, mercury, and lead. Samples were stored at $19{ }^{\circ} \mathrm{C}$, relative humidity (RH) minimum $15 \%$ and RH maximum $25 \%$. The selected soil samples were dried in an oven at $70{ }^{\circ} \mathrm{C}$ until the weight remained unchanged, and the samples were allowed to cool for at least $30 \mathrm{~min}$ on a desiccator. The soil samples were uniformly thickened in enamel or polyethylene vats, air dried in a place where they were not exposed to direct sunlight, and then shredded with wooden mallets. The principle of atomic absorption spectrophotometry is that the samples are dissociated through a pretreatment process to vaporize the neutral atom to form a specific wavelength that is transmitted through the base-state atomic binary vapor layer. It is applied to the analysis of harmful heavy metals and other elements in the sample by measuring the absorbance of each specific wavelength, such as photoelectric measurements, using the light absorbing field to quantify the element concentration in the sample. In this way, the pretreatment process differs depending on the type of heavy metals to be tested to vaporize the neutral reactors. There were five types of heavy metals to be tested (cadmium, copper, arsenic, mercury, and lead). Three of these (cadmium, copper, and lead) were used after pretreatment by decomposing the soil with royal flue. In the case of arsenic, it was preliminarily reduced to trivalent arsenic in a sample solution pretreated with the hydrolysis of the soil with aqua regia, and then hydrogenated while a reaction with sodium borohydride solution was atomized. Finally, in the case of mercury, the mercury vapor generated by reducing the atomic state by tin chloride solution was used. The pretreated sample solution was injected directly into the flame, atomized, and analyzed by atomic absorption spectrophotometry. The concentrations of heavy metals (cadmium, copper, arsenic, mercury, and lead) in the soil were determined by the following equation.

Concentration of heavy metals in soil $(\mathrm{mg} / \mathrm{kg})=\frac{\left(C_{1}-C_{0}\right)}{W_{d}} \times f \times q$

$\mathrm{C}_{1}$ : Heavy metal concentration of the analytical sample obtained from the calibration curve $(\mathrm{mg} / \mathrm{L})$

$\mathrm{C}_{0}$ : Heavy metal concentration of reagent base samples obtained from the calibration curve $(\mathrm{mg} / \mathrm{L})$

f: Dilution factor of the test solution (arsenic is 25 if out of the range of the calibration curve)

$\mathrm{V}$ : The volume of the test solution (here $0.1 \mathrm{~L}$ )

$\mathrm{W}_{\mathrm{d}}$ : Dry weight of the soil sample $(\mathrm{kg})$ 


\section{RESULTS AND DISCUSSION}

To determine the optimum culture medium concentration of the bank pollen, the bank pollen was placed in $10 \%, 15 \%$, and $20 \%$ sucrose medium, and $1 \mu \mathrm{L}$ or more per 24,48 , or $72 \mathrm{~h}$ was applied to the slide glass and the germination state of the pollen was observed with an optical microscope. The germination rate of bank pollen was determined by selecting two arbitrary points on the slide glass and selecting 25 flower pots in one place to confirm the germination state of the 50 flower pots. Pollen germination was not observed at $24 \mathrm{~h}$ or $48 \mathrm{~h}$ in the $10 \%$ pollen germination medium and the germination rate was $10 \%$ after $72 \mathrm{~h}$. In the $15 \%$ pollen germination culture, pollen germination was not observed at $24 \mathrm{~h}$ or $48 \mathrm{~h}$. After $72 \mathrm{~h}, 10 \%$ of pollen germinated and germination rate was the same as that of $10 \%$ pollen germination medium. The germination rate of the $20 \%$ pollen germination medium was not germinated at $24 \mathrm{~h}$ or $48 \mathrm{~h}$, but the germination rate of the pollen germination rate was the highest at $30 \%$ after $72 \mathrm{~h}$. The gingiva was not germinated until $48 \mathrm{~h}$ in all media, but germination progressed after $72 \mathrm{~h}$. Among them, germination rate was the highest for the germination rate of $30 \%$ in medium containing $20 \%$ sucrose (fig. 2). Therefore, we selected $20 \%$ sucrose medium as the optimal medium for the experiment

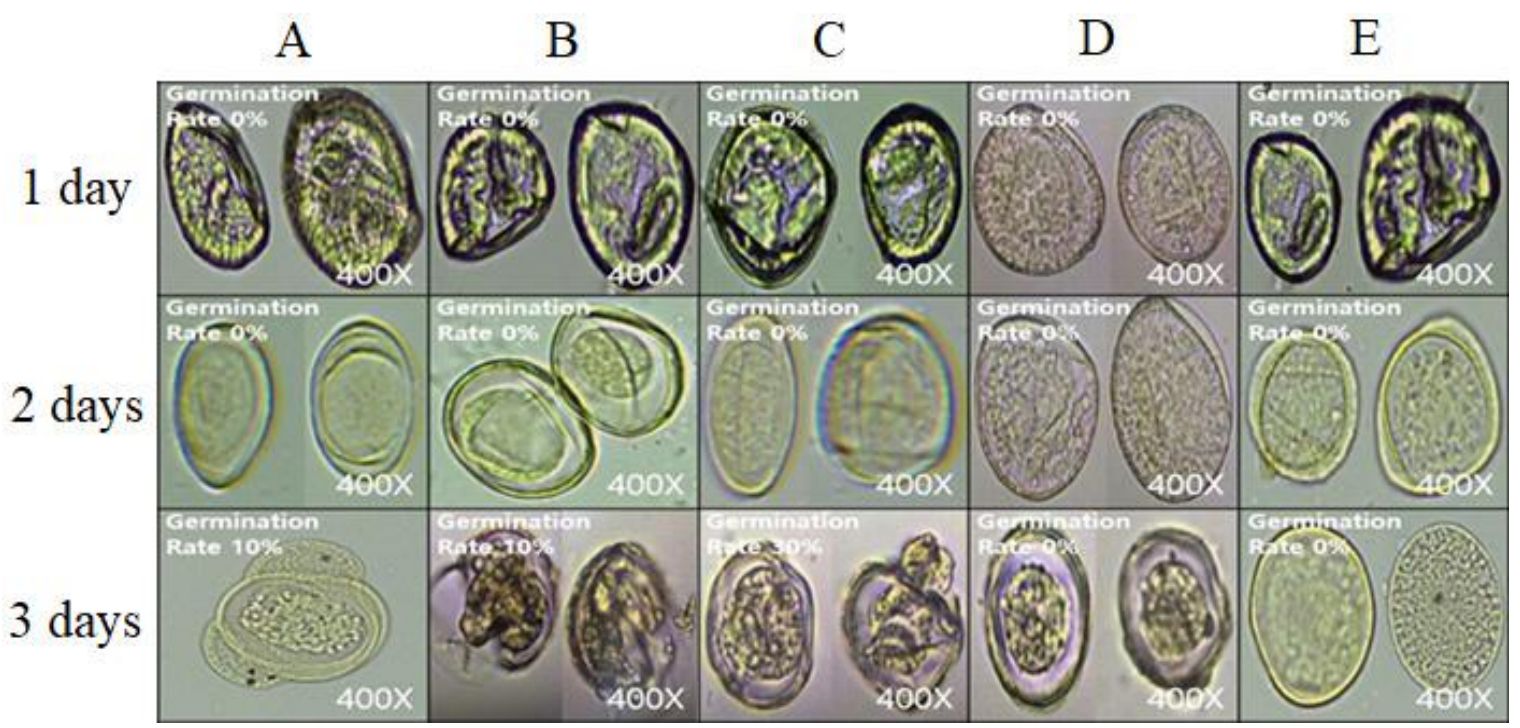

Fig2. Observation of ginkgo pollen germination rate by sucrose concentration. A : 10\% sucrose pollen media, B: $15 \%$ s sucrose pollen media, $C$ : $20 \%$ sucrose pollen media, D : Anti-pressure drug A type in media $(20 \%$ sucrose), E : Anti-pressure drug B type in media (20\% sucrose).

To confirm the inhibitory effect of the nanoparticulate agent on the pollen germination, a $20 \%$ sucrose-containing medium for the germination of bank pollen was used as a control group, and a nanoparticulate agent A (250 times water and diluted) and B (germination and dilution) were added to the experimental group. As a result, germination of pollen was not observed at $24 \mathrm{~h}$ or $48 \mathrm{~h}$ in $20 \%$ pollen germination control, but pollen germination was observed after $72 \mathrm{~h}$ (fig. 2). However, no germination of pollen was observed in $24 \mathrm{~h}, 48 \mathrm{~h}$, or $72 \mathrm{~h}$ in the medium supplemented with $1 \mu \mathrm{L}$ of nanoparticles. These results showed a substantial difference between that of the control medium, which showed a germination rate of $30 \%$ at $72 \mathrm{~h}$. Therefore, we determined that the addition of the nanotubular additives to the medium inhibited the germination of the bank pollen.

Nanoized emulsifiers were sprayed directly onto ginkgo trees. To determine the effect of the Ginkgo biloba. The pistil of the ginkgo was sprayed with a reding agent and its shape was observed. The morphological and component contents and distribution of gingko pistils were confirmed by EDS analysis. As a result of the EDS measurement, calcium and magnesium were abundant in the gill pistachios immediately after spraying the reding agent, but calcium and magnesium content decreased in the control. The 250-fold dilution and the 500-fold diluted bank stone after 4 days. It is believed that after 4 days of spraying, the calcium and magnesium components of the powder sprayed on the pistil of Ginkgo biloba flowed or was scattered by the external environment. Therefore, it is necessary to maximize the solubilization effect by re-spraying within 3 days to obtain the effective concentration on the Ginkgo biloba(fig. 3). 


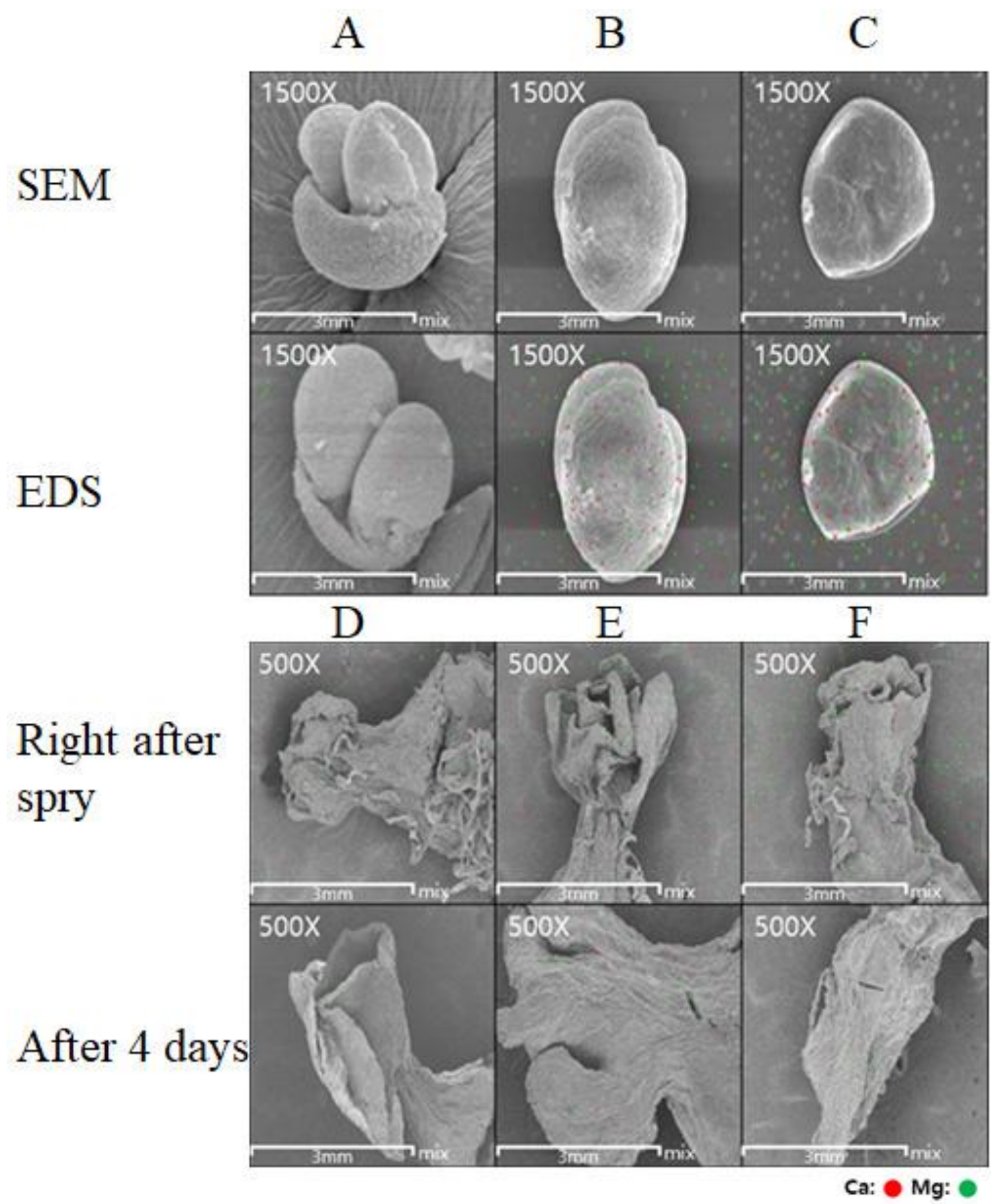

Fig3. Experimental electronic microscope. Observation of the Ginkgo pollen after spraying with anti-pressure drug. A: Control pollen, B: Anti-pressure drug A type pollen, C: Anti-pressure drug B type pollen. Observation of the effect of pistil coating on ginkgo after 4 days of spraying with nanosized deblossoming agent. D: Control Ginkgo biloba, E : Anti-pressure drug 500 dilution, $F$ : Anti-pressure drug 250 dilution.

SEM and EDS measurements were conducted to confirm the germination of the bank pollen in the medium supplemented with nanosized agonizing agents A and B. SEM can observe the appearance change of the pollen and EDS can observe the external state change of the pollen. Thus, the equipment can confirm the content of the pollen appearance. As a result of the SEM measurement, the bank pollen of the control was penetrated through the cell wall for pollen tube elongation, and the shape of the pollen germinated was observed. However, in the case of the pollen treated with the oxidizing agent, intact pollen was observed. In EDS, calcium and magnesium components were barely detected in the pollen of the control group, but calcium and magnesium components were observed around the pollen in the pollen added with the enhancing agent. These results indicate that the calcium and magnesium components of the reding agent encircled the pollen and prevented pollen germination. 
To confirm the effect of nanosized re-deposition agent on nano-grinding equipment, we sprayed red pepper powder directly on ginkgoes, and confirmed the fruit yield efficacy. Five of Gyeonggi Province and three of Gyeongsangbuk-do Province were selected and five were sprayed with red pepper spray as a control group, whereas five were sprayed with red pepper spray. The solutions were sprayed three times at intervals of 2-3 days. To confirm their efficacy on Ginkgo biloba, the fruits were photographed in the control and experimental groups in April when the Ginkgo biloba was fruitless. To confirm the efficacy of the nanoized emulsifiers, four ginkgo trees were selected from Baeam-myeon, Gyeonggi-do, and Gwacheon-si, Gyeonggi-do and sprayed three times at intervals of 2-3 days beginning April 30, 2016 (table 1). As a result, it was confirmed that the ginkgo fruit of the experimental group was reduced by $60-95 \%$ or more.To confirm the efficacy of nanoized emollients, two ginkgo trees were selected from Gangsan, Daegu, Catholic University, Gyeongsanbuk, Gyeongsangbuk-do, and sprayed three times at intervals of 2-3 days beginning on April 15, 2016. As a result, it was confirmed that the ginkgo fruit of the experimental group was reduced by $80-90 \%$ or more. As a result, it was confirmed that the nano-processing agent applied to Ginkgo biloba directly by using the nano-process technology was effective (fig. 4, table 2).

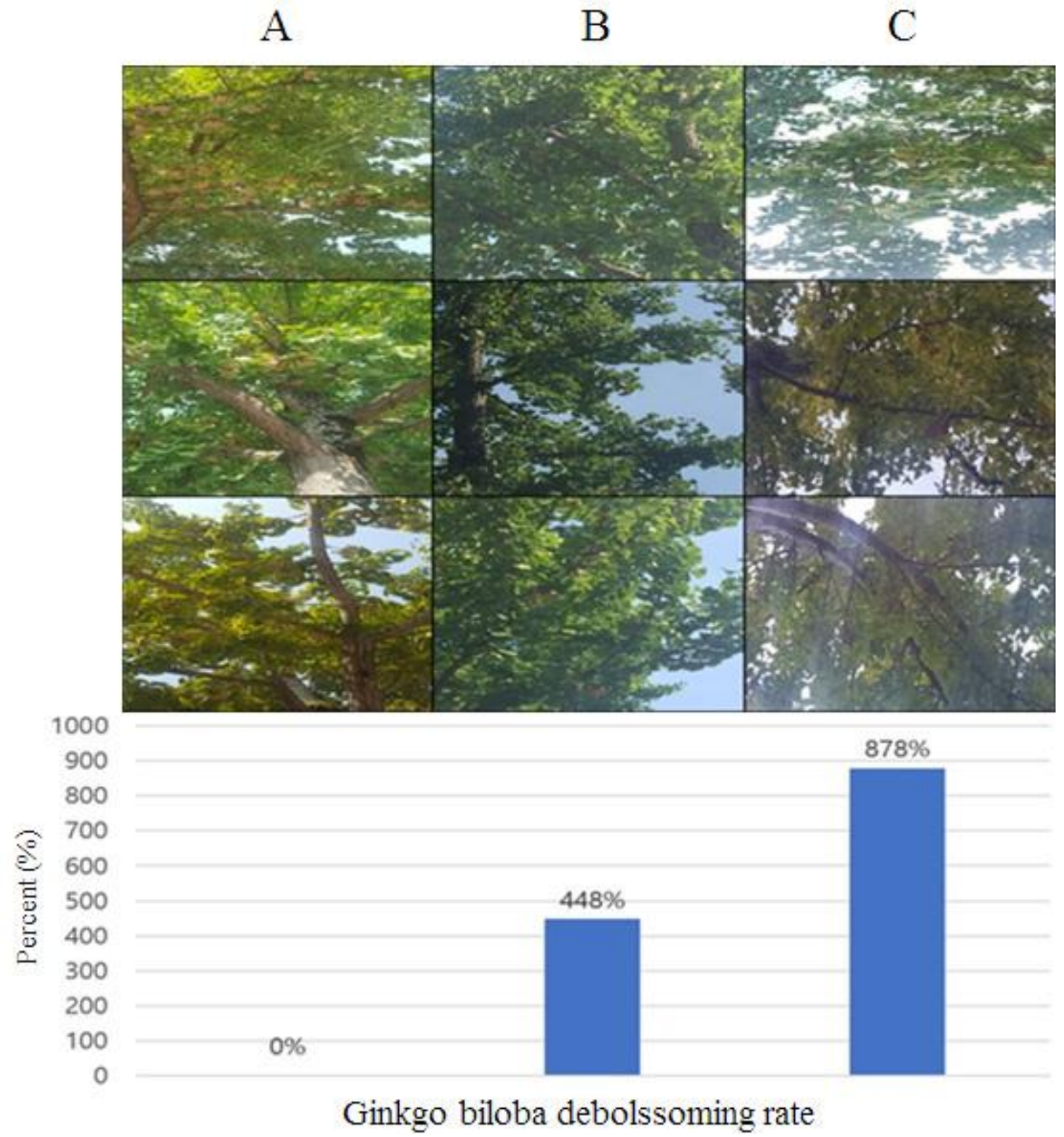

Fig4. Observation Ginkgo biloba deblossoming rate. A: Control Ginkgo biloba, B: Anti-pressure drug 250 dilution, C: Anti-pressure drug 500 dilution 
Table1. Gyeonggi-do ginko spread interval and effect

\begin{tabular}{|c|c|c|c|c|c|}
\hline $\begin{array}{l}\text { Number } \\
\text { of Sprays }\end{array}$ & Spray section & Characteristic & Effect $(\%)$ & Status & $\begin{array}{c}\text { Date of } \\
\text { observation }\end{array}$ \\
\hline 3 & $\begin{array}{l}\text { Baegam-myeon, Cheoin-gu, } \\
\text { Yongin-si, Gyeonggi-do, Korea }\end{array}$ & Greenbelt & 80 & \multirow{5}{*}{$\begin{array}{l}\text { - } \\
21 / 5000 \\
\text { silheomgungwa } \\
\text { daejogun-uiyug- } \\
\text { anbigyoga } \\
\text { ganeungham. } \\
\text { Visual comparison } \\
\text { of experimental } \\
\text { group and control } \\
\text { group is possible. }\end{array}$} & \multirow{5}{*}{$\begin{array}{l}\text { April } 16- \\
\text { April 30, } \\
2016\end{array}$} \\
\hline 3 & $\begin{array}{c}\text { Munwon-ro, Gwacheon-si, } \\
\text { Gyeonggi-do, Korea }\end{array}$ & Street trees & 90 & & \\
\hline 3 & $\begin{array}{c}\text { Dolma-ro, Bundang-gu, } \\
\text { Seongnam-si, Gyeonggi-do, } \\
\text { Korea }\end{array}$ & Street trees & 60 & & \\
\hline 3 & $\begin{array}{c}\text { Naejeong-ro, Bundang-gu, } \\
\text { Seongnam-si, Gyeonggi-do, } \\
\text { Korea }\end{array}$ & Street trees & 95 & & \\
\hline 3 & $\begin{array}{c}\text { Songjeong-ro, Jangan-gu, } \\
\text { Suwon-si, Gyeonggi-do, Korea }\end{array}$ & Street trees & 70 & & \\
\hline
\end{tabular}

Table2. ginko spreading area and effect in Gyeongsangbuk-do

\begin{tabular}{|c|c|c|c|c|c|}
\hline $\begin{array}{c}6 / 5000 \\
\text { salpo hoes-su } \\
\text { Number of Sprays }\end{array}$ & Spray section & Characteristic & Effect (\%) & Status & $\begin{array}{c}\text { Date of } \\
\text { observation }\end{array}$ \\
\hline 3 & $\begin{array}{l}\text { The side of a } \\
\text { cathedra at The } \\
\text { main gate of } \\
\text { Daegu Catholic } \\
\text { University }\end{array}$ & Street trees & 90 & \multirow{3}{*}{$\begin{array}{l}\text {-The effect of } \\
\text { experimental group } \\
\text { and control group is } \\
\text { very large. } \\
\text { - Confirm the effect } \\
\text { difference according to } \\
\text { the spraying method. }\end{array}$} & \multirow{3}{*}{$\begin{array}{r}\text { March } 25 \\
\sim \text { April } \\
15,2016\end{array}$} \\
\hline 3 & $\begin{array}{c}\text { The side of } \\
\text { adormitory at } \\
\text { The main gate of } \\
\text { Daegu Catholic } \\
\text { University }\end{array}$ & Street trees & 80 & & \\
\hline 3 & $\begin{array}{c}\text { st. science hall at } \\
\text { Daegu Catholic } \\
\text { University }\end{array}$ & Street trees & 95 & & \\
\hline
\end{tabular}

To examine the contamination of the soil where the reding agent was sprayed, $1 \mathrm{~kg}$ of soil was collected from the sprayed area and the unsprayed area. Each soil was sampled and the process test was conducted (table 3 ).In the case of the soil pollution criterion, the roads were based on the values of the three regions. The area included factory sites, parking lots, gas station ponds, roads, railroad pavilions, and banks. As a result of the tests, it was confirmed that the application of the reding agent did not affect the soil contamination because the cadmium, copper, arsenic, mercury, and lead did not meet the criterion of a soil pollution concern.

Table3. Soil pollution process test result in Gyeonggi province after spraying

\begin{tabular}{|c|c|c|c|c|c|c|}
\hline \multicolumn{7}{|c|}{ Test result } \\
\hline \multirow[t]{2}{*}{ Test } & \multicolumn{3}{|c|}{ Criteria for soil pollution concerns } & \multicolumn{2}{|c|}{ Result $(\mathrm{mg} / \mathrm{kg})$} & \multirow[t]{2}{*}{ Remarks } \\
\hline & 1area & 2area & 3area & Sprayed & Unsprayed & \\
\hline Cadmium & 4 & 10 & 60 & 0.26 & 0.47 & - \\
\hline Copper & 150 & 500 & 2,000 & 50.5 & 96.5 & - \\
\hline Arsenic & 25 & 50 & 200 & 6.06 & 9.81 & \\
\hline Mercury & 4 & 10 & 20 & 0.26 & 0.30 & \\
\hline Lead & 200 & 400 & 700 & 29.5 & 48.2 & \\
\hline
\end{tabular}

\section{CONCLUSION}

We have developed a technique to control the ginkgo fruit of the ginkgo and soil pollution using the wet nanotechnology. Therefore, it is thought that this technology will greatly contribute to human health and happiness. 


\section{ACKNOWLEDGEMENT}

This study was carried out with the support of R\&D Program for Forest Science Technology (Project No. "2016018B10-1719-AB02") provided by Korea Forest Service(Korea Forestry Promotion Institute).The money mentioned has nothing to do with the publication of the manuscript.

\section{DATA AVAILABILITY}

The dataset generated during this study is available from the corresponding author on reasonable request.

\section{REFERENCES}

[1] Wada, K. Ishigaki, S. Ueda, K. Sakata, M. Haga, M. "An antivitamin B6, 4'-methoxypyridoxine, from the seed of Ginkgo biloba L.," Chem Pharm Bull p. 33, 1985.

[2] Singh, B. Kaur, P. Gopichand, Singh, R.D. Ahuja, P.S. "Biology and chemistry of Ginkgo biloba," Fitoterapia 79(6):p. 401-18, 2008.

[3] Yamaguchi, T. "New method of rice seed disinfection in Japan," Review of Plant Protection Research 10:p. 49-59, 1977.

[4] Jung, J. Rho, Y.I. "Generalized convulsions caused by overconsumption of Ginkgo nuts in 6 year-old male," J Kor Child Neurology Soc 18(1): p. 129-32, 2010.

[5] Kajiyama, Y. Fujii, K. Takeuchi, H. Manabe, Y. “Ginkgo seed poisoning," Pediatrics 109(2): p. 325-27, 2002.

[6] Byers, R.E. "Flower and fruit thinning and vegetative: fruiting balance," In: Ferree, D.C. Warrington, I.J. (Eds.), Apples: botany, production and uses. Ebooks on agriculture and the applied life sciences from CAB International, pp. 409-36, 2003.

[7] Mahvash, A. Bahram, B. Ali, A.R. Mohsen, P. " Fruitlet chemical thinners affect yield, fruit quality, and leaf and fruit mineral composition of 'Soltani' apple," Hortic Environ Biotechnol 50(5):p. 401-405, 2009.

[8] Kim, D.W. Lee, H.S. Jung, C.E. "Toxicity of the lime sulfur as a flower thinner of apple to the honey bee, Apis mellifera L. and other pollinators," Korean J Apic 23: p. 43-50, 2008.

[9] Zhang, M. Zhang, C.J. Shrestha, S. "Study on the preparation technology of superfine ground powder of Agrocybe chaxingu Huang," J Food Eng 67(3): p. 333-7, 2005.

[10] Brewvaker, J.L. Kwack, B.H. "The essential role of calcium ion in pollen germination and pollen tube growth,” Am J Bot 50(9): p. 859-65, 1963.

[11] Yoo, J.G. Kang, B.K. Kim, D.H. Lee, J.W. Lee, D.H. Kweon, H.J. Choi, I.M. Jung, H.Y. Choung, M.G. Choi, D.G. Kang, I.K. "Effect of flower and fruit thinner on fruit set and fruit quality of 'Gamhong' apples," Horticul Sci Techno 34(1): p. 24-31, 2016.

[12] Park, S.G. Kwon, S.J. Kim, Y.M. Lee, S.S. "Reaction properties of non-cement mortar using ground granulated blast furnace slag," J Korea Conte Assoc13(9): p. 392-99, 2013.

[13] Kim, G.H. Jeon, Y.J. Byun, H.G. Lee, Y.S. Lee, E.H. Kim, S.K. "Effect of calcium compounds from oyster shell bound fish skin gelatin peptide in calcium deficient rats," J Korean Fish Soc 31(2): p. 149-59, 1998.

[14] Joy, D. C. “The theory and practice of high-resolution scanning electron microscopy,"Ultramicroscopy 37(1-4): p.216-33, 1991.

Citation: Seung Hyun Lee et al., "Influence of Enzymatic Agents on the Ginkgo Fruit Ratio using NanoProcessing Technology", International Journal of Forestry and Horticulture (IJFH), vol. 4, no. 3, pp. 16-24, 2018. http://dx.doi.org/10.20431/2454-9487.0403003

Copyright: (C) 2018 Authors. This is an open-access article distributed under the terms of the Creative Commons Attribution License, which permits unrestricted use, distribution, and reproduction in any medium, provided the original author and source are credited. 